Original article

\title{
Clinical and functional ultra-long-term outcome of patients with a clinical high risk (CHR) for psychosis
}

\author{
Katharina Beck ${ }^{\mathrm{a}, \mathrm{b}}$, Erich Studerus ${ }^{\mathrm{a}, \mathrm{c}}$, Christina Andreou ${ }^{\mathrm{a}}$, Laura Egloff ${ }^{\mathrm{b}, \mathrm{f}}$, \\ Letizia Leanza $^{\mathrm{a}, \mathrm{b}}$, Andor E. Simon ${ }^{\mathrm{d}, \mathrm{e}}$, Stefan Borgwardt ${ }^{\mathrm{f}}$, Anita Riecher-Rössler ${ }^{\mathrm{g}, *}$ \\ a University of Basel Psychiatric Hospital, Center for Gender Research and Early Detection, Basel, Switzerland \\ ${ }^{\mathrm{b}}$ University of Basel, Division of Clinical Psychology and Epidemiology, Department of Psychology, Basel, Switzerland \\ c University of Basel, Department of Psychology, Division of Developmental and Personality Psychology, Basel, Switzerland \\ d University Hospital of Psychiatry and Psychotherapy, University of Bern, Switzerland \\ e Specialized Early Psychosis Outpatient Service for Adolescents and Young Adults, Department of Psychiatry, Bruderholz, Switzerland \\ ${ }^{\mathrm{f}}$ Department of Psychiatry, University of Basel Psychiatric Hospital, Basel, Switzerland \\ g University of Basel, Basel, Switzerland
}

\section{A R T I C L E I N F O}

\section{Article history:}

Received 14 May 2019

Received in revised form 15 August 2019

Accepted 26 August 2019

Available online 9 September 2019

\section{Keywords:}

At-risk mental state

Remission

Functioning

Recovery

Symptomatology

Comorbidity

\begin{abstract}
A B S T R A C T
Background: Few studies have followed up patients with a clinical high risk (CHR) for psychosis for more than 2-3 years. We aimed to investigate the rates and baseline predictors for remission from CHR and transition to psychosis over a follow-up period of up to 16 years. Additionally, we examined the clinical and functional long-term outcome of CHR patients who did not transition.

Methods: We analyzed the long-term course of CHR patients that had been included in the longitudinal studies "Früherkennung von Psychosen" (FePsy) or "Bruderholz" (BHS). Those patients who had not transitioned to psychosis during the initial follow-up periods ( $2 / 5$ years), were invited for additional follow-ups.

Results: Originally, 255 CHR patients had been included. Of these, 47 had transitioned to psychosis during the initial follow-ups. Thus, 208 were contacted for the long-term follow-up, of which 72 (34.6\%) participated. From the original sample of $255,26 \%, 31 \%, 35 \%$, and $38 \%$ were estimated to have transitioned after $3,5,10$, and 16 years, respectively, and $51 \%$ had remitted from their high risk status at the latest follow-up. Better psychosocial functioning at baseline was associated with a higher rate of remission. Of the 72 CHR patients re-assessed at long-term follow-up, 60 had not transitioned, but only $28 \%$ of those were fully recovered clinically and functionally.

Conclusions: Our study shows the need for follow-ups and clinical attention longer than the usual 2-3 years as there are several CHR patients with later transitions and only a minority of CHR those without transition fully recovers.
\end{abstract}

(c) 2019 Elsevier Masson SAS. All rights reserved.

\section{Introduction}

The majority of patients with schizophrenic psychoses experience a prodromal phase with first signs and symptoms, beginning on average 3-4 years before the onset of frank psychosis [1,2]. Based on this evidence, the concept of the clinical high risk (CHR) state for psychosis was developed approximately two decades ago, including specified criteria such as the presence of attenuated psychotic symptoms, short limited psychotic symptoms or genetic risk and functional decline [3].

\footnotetext{
* Corresponding author at: University of Basel, Basel, Switzerland.

E-mail address: anita.riecher-roessler@unibas.ch (A. Riecher-Rössler).
}

A large body of research has since been conducted to establish and optimize early detection of the early stages of the disorder and to predict transition to frank psychosis. Current meta-analytical evidence indicates that about $20 \%$ of CHR patients develop frank psychosis [4] and about 35\% remit from their CHR state [5] within two years after initial identification. The speed of psychosis progression tends to plateau from the third year on, reaching a cumulative transition risk of about $35 \%$ after 10 years [6]. Therefore, most previous studies have focused on the first 2-3 years after initial identification [7-9] and there is only little evidence on the long-term outcome of CHR patients [10-15].

Although CHR patients without later transition (CHR-NT patients) make up the majority of CHR samples [4,9], little is known about their clinical and functional long-term outcome. So 
far, there are only very few studies evaluating non-psychotic clinical and functional outcome of CHR-NT patients with follow-up durations of more than 2 years [10-12,15]. These studies indicate that even CHR patients without transition to frank psychosis experience (subclinical) psychotic symptoms, non-psychotic disorders and psychosocial impairments in the long-term [10-12,15], although most of the comorbid disorders seem to be already present at baseline $[16,17]$.

However, the existing long-term studies on CHR-NT patients have several methodological limitations. Functional outcome was frequently assessed by the GAF in which the level of functioning is rated based on psychosocial functioning or clinical symptoms, whichever area is more impaired, leading to a conflation of both. Most studies reported rates of remission from the CHR state only for certain points in time. Furthermore, a risk estimate that takes into account the "competing" risk of transition and the usually considerable proportion of drop-outs was rarely provided.

Little is known about how many CHR patients transition to frank psychosis and how many remit from their clinical high risk state in the long term. Furthermore, limited information is available on the clinical and functional outcome of those who do not transition, e.g., regarding subclinical psychotic symptoms, non-psychotic clinical symptoms and diagnoses such as depression and anxiety, psychosocial functioning and overall recovery. Insight into the long-term outcome of CHR-NT patients could inform clinical service planning and future research on the CHR state.

In this study, we therefore thoroughly investigated the ultralong-term course (up to 16 years) of CHR patients, evaluating transitions to psychosis over the whole follow-up period including late transitions. Furthermore, we assessed the clinical and functional outcome of those without transition, i.e., the rates of remission from the CHR state, clinical symptoms and axis I diagnoses, functional outcome, and the prevalence of full clinical and functional recovery. Moreover, we aimed to investigate predictors of clinical and functional outcome in CHR-NT patients at long-term follow-up as to the best of our knowledge this has not previously been investigated. Based on a systematic review [15], we expected that most CHR-NT patients do not recover functionally and clinically during several years of follow-up.

\section{Methods}

\subsection{Participants and procedure}

Patients with a clinical high risk (CHR) for psychosis were recruited via the prospective Früherkennung von Psychosen (FePsy) study [18,19] and the Bruderholz study (BHS) [20]. Both were prospective clinical studies of all consecutive referrals from defined catchment areas to the specialized early detection centers of the counties of Basel city (FePsy) and Basel countryside (BHS). Patients received treatment according to needs, case-management, and supportive psychotherapy during the follow-up. Antipsychotic treatment was only initiated after transition to psychosis had occurred. Further details regarding the characteristics of the studies can be found in Table 1 and in previous publications [18-20]. Both studies were approved by the Ethics Committee northwest/central Switzerland (EKNZ) and all participants provided written informed consent. If subjects were under age 18 , additional written informed consent was obtained from their parents.

All CHR patients who did not transition to frank psychosis during the respective initial follow-up periods, including patients who dropped out and did not complete all planned follow-up assessments, were regarded as patients without initial transition (CHR-NT), and were asked to take part in the long-term follow-up assessment of the current study (see Supplementary Materials page 1 for detailed information on the very thorough contact procedure).

Patients who refused to participate in the extensive long-term follow-up examination were asked to participate in a shorter telephone interview instead.

\subsection{Measures}

\subsubsection{Baseline assessment}

Baseline parameters and measures are reported in Table 1.

\subsubsection{Follow-up assessments}

CHR status was re-evaluated at each follow-up visit using the positive symptom items of the Brief Psychiatric Rating Scale Expanded (BPRS-E) $[22,23]$ in the FePsy study and the Structured Interview for Prodromal Symptoms/Scale of Prodromal Symptoms (SIPS/SOPS) [24,25] in the Bruderholz study.

Remission from CHR. Remission from CHR was defined as the absence of attenuated psychotic symptoms (APS) or brief limited intermittent psychotic symptoms (BLIPS), i.e., sub-threshold severity scores on all positive symptom items of the BPRS-E (FePsy) or SOPS (BHS) for at least 12 consecutive months preceding the latest follow-up assessment. Thus, in the FePsy study, the four BPRS-E symptoms relevant for this assessment had to be constantly under the following thresholds: suspiciousness $\leq 2$, hallucinations $\leq 1$, unusual thought content $\leq 2$, and formal thought disorder $\leq 2$. In the Bruderholz study, the five positive psychotic symptom items of the SOPS had to be constantly $\leq 2$. Both sets of criteria are similar to those used by Schlosser et al. [26]. The date of remission was defined as the date at which the APS/ BLIPS-free period lasting at least 12 months started. In those CHRNT patients who participated in the long-term follow-up assessment, the date of remission was determined retrospectively for the whole follow-up period including the initial follow-up period. In those patients who did not take part in the long-term assessment, remission was evaluated by using all BPRS-E/SOPS positive symptom ratings of the initial follow-up period.

Transition to psychosis according to the criteria by Yung and colleagues [3] was also evaluated not only at each follow-up assessment but also retrospectively for the entire follow-up period by considering all available information, including medical records.

Non-remission from $C H R$. In case neither remission from $\mathrm{CHR}$ nor transition to psychosis occurred, patients were considered non-remitted at the time point they were last seen. This was the date of the long-term follow-up visit for patients participating in the long-term follow-up, whereas for patients not participating in the long-term follow-up this was the last visit in the initial follow-up.

Psychosocial functioning in CHR-NT patients at long-term follow-up, referring to the preceding 4 weeks, was evaluated by the Personal and Social Performance scale (PSP) [27] which is based on the Social and Occupational Functioning Scale (SOFAS) [28] and has been validated in many languages, including German [29]. Functioning is assessed in four domains, i.e., occupational functioning, interpersonal relationships, self-care, and presence of disturbing/aggressive behavior. Overall functioning is expressed in a global score. For the current study a global score of $\leq 70$ was defined as functional impairment since scores above 70 indicate no or mild dysfunction [27].

The Structured Clinical Interview for DSM-IV Axis I Disorders (SCID-I) [30,31] was used to assess current axis I diagnoses in CHRNT patients at long-term follow-up.

Full clinical and functional recovery at long-term follow-up was defined as meeting all of the following criteria: no transition to frank psychosis, remission from CHR, good functional outcome 
Table 1

Characteristics of the FePsy and Bruderholz studies.

\begin{tabular}{|c|c|c|}
\hline & FePsy study & Bruderholz study \\
\hline Inclusion period: & - $3 / 01 / 2000-07 / 31 / 2014$ & - $2003-2006$ \\
\hline Initial follow-up: & $\begin{array}{l}\text { - up to 5-7 years } \\
\left.\left.\text { - monthly ( } 1^{\text {st }} \text { year }\right), 3-\text { monthly ( } 2^{\text {nd }} \text { and } 3^{\text {rd }} \text { year }\right) \text {, and annually } \\
\text { thereafter }\end{array}$ & $\begin{array}{l}\text { - up to } 2 \text { years } \\
\text { - 3-monthly to annually }\end{array}$ \\
\hline \multirow[t]{2}{*}{ CHR criteria } & $\begin{array}{l}\text { Risk criteria according to BSIP: } \\
\text { - Attenuated psychotic symptoms (APS) } \\
\text { - Brief limited intermittent psychotic symptoms (BLIPS) } \\
\text { - Genetic risk and combination of certain prodromal symptoms/risk } \\
\text { factors, including deterioration in functioning (GRD) }\end{array}$ & $\begin{array}{l}\text { UHR criteria according to SIPS/SOPS: } \\
\text { - Attenuated psychotic symptoms (APS) } \\
\text { - Brief limited intermittent psychotic symptoms (BLIPS) } \\
\text { - Genetic risk and deterioration syndrome (GRD) }\end{array}$ \\
\hline & $\begin{array}{l}\text { - Unspecific risk category (URC), i.e., combination of a minimum } \\
\text { number of certain predefined prodromal symptoms/risk factors }\end{array}$ & $\begin{array}{l}\text { Basic symptom criterion: } \\
\text { - At least one "predictive basic symptom" [1] with a SPI-A score } \geq 3\end{array}$ \\
\hline Exclusion criteria & $\begin{array}{l}\text { - age }<18 \text { years } \\
\text { - IQ }<70 \\
\text { - previous psychotic episode (with transition acc. to Yung et al. [3] } \\
\text { - antipsychotic treatment for }>3 \text { weeks (lifetime) and/or total amount } \\
\text { of } \\
\text { - } \geq 2500 \text { mg chlorpromazine equivalents } \\
\text { - (pre-)psychotic symptoms only within a clearly diagnosed affective } \\
\text { psychosis or borderline personality disorder } \\
\text { - (pre-)psychotic symptoms clearly due to organic reasons or } \\
\text { - insubstance abuse only }\end{array}$ & $\begin{array}{l}\text { - age }<14 \text { years } \\
\text { - IQ }<70 \\
\text { - previous psychotic episode } \\
\text { - traumatic brain injury, epilepsy or other known neurological } \\
\text { disorder } \\
\text { - other significant medical condition considered to affect cognitive } \\
\text { performance and self-perception }\end{array}$ \\
\hline \multicolumn{3}{|c|}{ Baseline measures at initial study intake } \\
\hline CHR criteria & - BSIP & $\begin{array}{l}\text { - SIPS/SOPS } \\
\text { - SPI-A }\end{array}$ \\
\hline $\begin{array}{l}\text { Positive \& negative } \\
\text { symptoms }\end{array}$ & - BPRS-E [2] & - PANSS \\
\hline $\begin{array}{l}\text { Psychosocial } \\
\text { functioning }\end{array}$ & - GAF & - GAF \\
\hline Axis I diagnoses & - SCID-I for DSM-IV & - SCID-I for DSM-IV \\
\hline Cannabis use & - Basel Interview for Psychosis (BIP) & - Bruderholz Demography Questionnaire (BDQ) \\
\hline Transition criteria & - acc. to Yung et al [3]; BPRS-E & - acc. to Yung et al [3]; SOPS \\
\hline
\end{tabular}

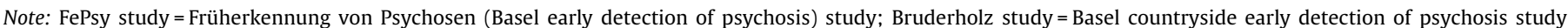

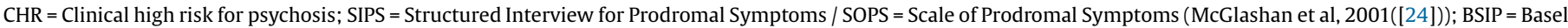

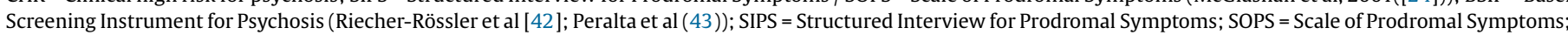

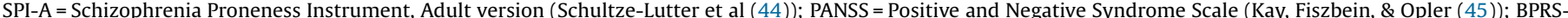

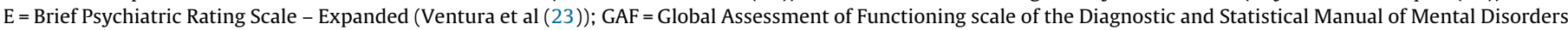

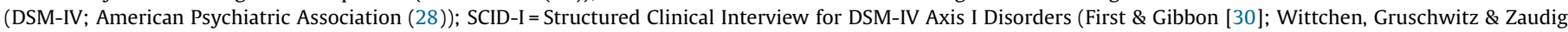
(31)); BIP (Riecher-Rössler et al (46)).

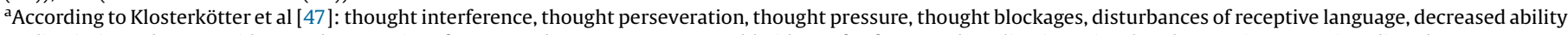
to discriminate between ideas and perception, fantasy and true memory, unstable ideas of reference, derealization, visual and acoustic perception disturbances.

${ }^{\mathrm{b}}$ Positive and negative symptom subscales according to Shafer et al ([21]).

(PSP global score $>70$ ), and the absence of any current axis I disorder in accordance with Rutigliano et al. [32].

\subsection{Statistical analyses}

Statistical analyses were conducted using the R environment for statistical computing [33]. Analyses were conducted in two different samples: 1 ) the initial baseline sample of all CHR patients and 2) the sample of CHR patients who participated in the longterm follow-up assessment of the current study and had not transitioned to frank psychosis during the whole follow-up period. To test the representativity of the second sample, we compared those who participated in the long-term follow-up assessment with those who did not regarding various socio-demographic and clinical characteristics - both at baseline and at their last visit of the initial follow-up period.

In the first sample we investigated of CHR remission and transition rates over the whole follow-up period using cumulative incidence curves (CIC) which are the competing risks analogs of
Kaplan-Meier survival curves [34]. We used proportional causespecific hazards models to investigate baseline predictors for remission from CHR and transition to psychosis, i.e., age and gender, positive symptoms, negative symptoms, psychosocial functioning, and current cannabis use.

In the second sample we conducted 1) logistic and 2) multiple regression analyses to examine the predictive value of the aforementioned baseline socio-demographic and clinical variables regarding 1) remission from $\mathrm{CHR}$ and 2) psychosocial functioning at the long-term follow-up assessment. For each predictor variable, a separate model was fitted that additionally included study (FePsy vs. BHS) as covariate.

\section{Results}

\subsection{Initial baseline sample (all CHR patients)}

The initial baseline sample consisted of $255 \mathrm{CHR}$ patients. The average follow-up duration (mean $\pm \mathrm{SD}$; range) of the whole 
initial sample was $3.9 \pm 4.1$ (range: $0-16.6$ ), of those with later transition $2 \pm 2.5(0.01-11.21)$, and of those without transition $8.2 \pm 4.4(0.1-16.6)$ years, respectively.

\subsection{Ultra-long-term follow-up sample of CHR-NT patients}

Forty-seven CHR patients of the initial baseline sample had been detected to have had transitioned to frank psychosis during initial follow-up. Thus, 208 CHR patients without initially detected transition (CHR-NT) were contacted and invited to participate in the ultra-long-term follow-up assessment. Of these, 72 (34.6\%) did participate (71 face-to-face interviews, 1 telephone interview), 28 (13.5\%) refused to take part, and 108 (51.9\%) could not be reached. For two further patients only medical records were available, including information on transition status. Twelve patients participating in the long-term follow-up assessment turned out to have had transitioned in the meantime. Therefore, the long-term sample of CHR-NT patients consisted of 60 participants. Further details on the study sample can be found in Fig. 1 and Table 2.

There were no significant group differences between CHR patients who participated in the long-term follow-up assessment $(n=72)$ and those who did not $(n=183)$ regarding various sociodemographic and clinical variables (all p-values $>0.05$; data available upon request), indicating a high representativity of the long-term follow-up sample.

\subsection{Clinical outcome of the total initial CHR sample $(n=255)$}

\subsubsection{Rates of transition to psychosis}

Overall, 60 patients had transitioned to frank psychosis. At 2-, 3-, 4-, and 5-year follow-up the estimated transition rates were $18.7 \%, 23.1 \%, 25.9 \%$, and $30.8 \%$, respectively. Ten and 15 years after baseline the rates were $34.9 \%$ and $38.2 \%$, respectively (for the proportions of transitions for each year see Fig. 2 and Table S2).

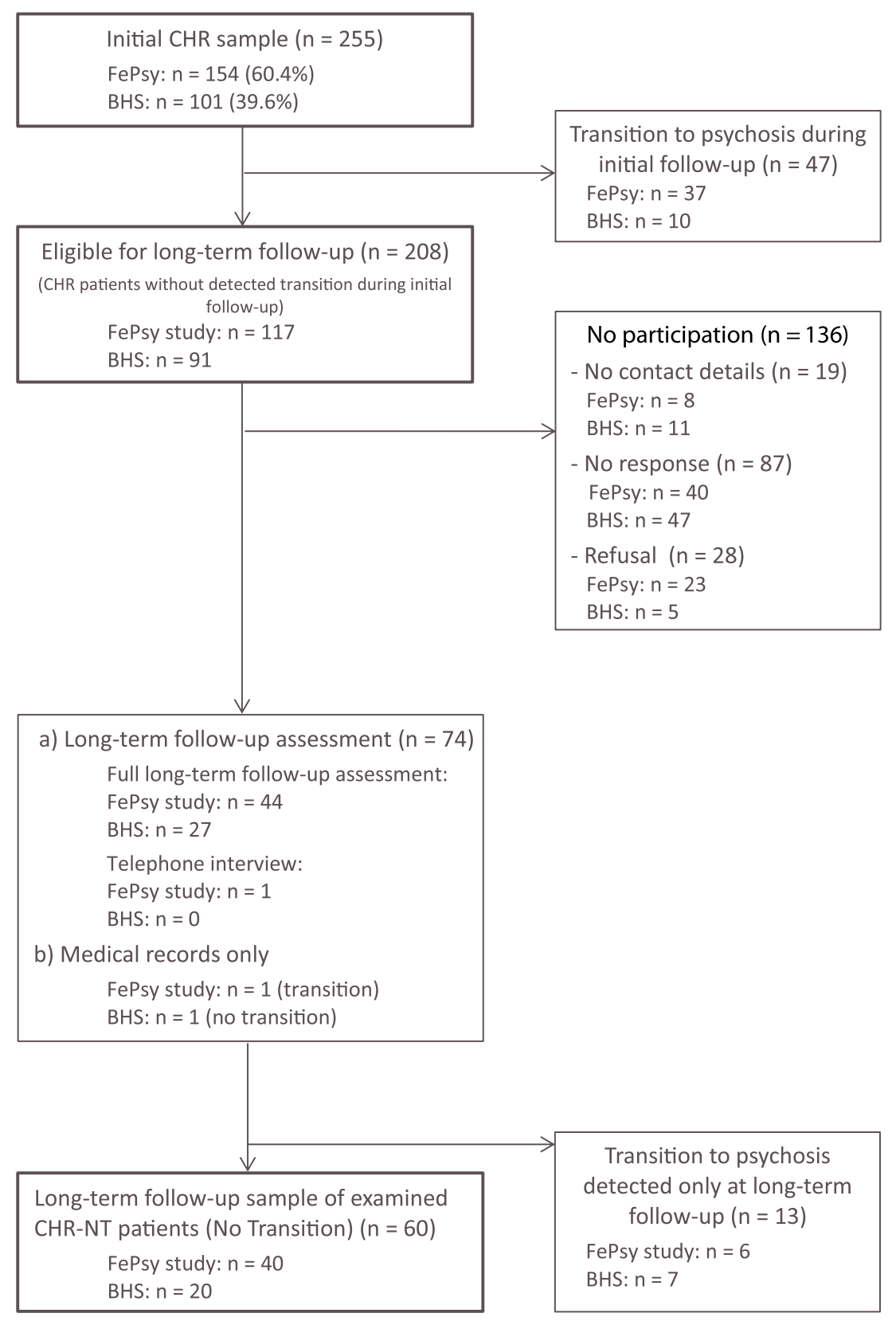

Fig. 1. Flow diagram of the study population. 
Table 2

Socio-demographic and clinical characteristics of the CHR-NT patients of the long-term follow-up sample ( $\mathrm{n}=60)$ at baseline and long-term follow-up.

\begin{tabular}{|c|c|c|c|c|c|c|}
\hline & \multicolumn{2}{|l|}{ FePsy study $(n=40)$} & \multicolumn{2}{|c|}{ Bruderholz study $(n=20)$} & \multicolumn{2}{|l|}{ Total sample $(n=60)$} \\
\hline & $\mathrm{M}$ (SD; range) & $\mathrm{n}(\%)$ & $\mathrm{M}$ (SD; range) & $\mathrm{n}(\%)$ & M (SD; range) & $\mathrm{n}(\%)$ \\
\hline \multicolumn{7}{|l|}{ Baseline } \\
\hline Age, years & $26(8.7 ; 18.2-56.8)$ & & $20.2(5.7 ; 14.4-35.6)$ & & $24.1(8.2 ; 14.4-56.8)$ & \\
\hline Gender, male & & $26(65)$ & & $15(75)$ & & $41(68.3)$ \\
\hline Education, years & $12.4(3 ; 8-19)$ & & $14.7(3.3 ; 9-23)$ & & $13.1(3.3 ; 8-23)$ & \\
\hline $\begin{array}{l}\text { Positive symptoms } \\
\text { (BPRS-E/PANSS) }\end{array}$ & $5.1(2.2 ; 3-13)$ & & $5.5(1.5 ; 3-8)$ & & $5.2(2 ; 3-13)$ & \\
\hline $\begin{array}{l}\text { Negative symptoms } \\
\text { (BPRS-E/PANSS) }\end{array}$ & $5.7(3 ; 3-14)$ & & $3.9(1.6 ; 3-7)$ & & $5.3(2.8 ; 3-14)$ & \\
\hline Psychosocial functioning (GAF) & $58.8(10.2 ; 42-90)$ & & $43.8(12.6 ; 0-58)$ & & $53.6(13.1 ; 0-90)$ & \\
\hline Current cannabis use (BIP), yes & & $7(17.5)$ & & $1(5)$ & & $8(13.3)$ \\
\hline \multicolumn{7}{|l|}{ Long-term follow-up } \\
\hline Age at follow-up, years & $34(11.4 ; 21.3-72.4)$ & & $31.1(6.2 ; 24.1-48.8)$ & & $33(10 ; 21.3-72.4)$ & \\
\hline \multicolumn{7}{|l|}{ CHR state (BPRS- E/PANSS) } \\
\hline Remission & & $33(82.5)$ & & $18(90)$ & & $51(85)$ \\
\hline Non-remission & & $7(17.5)$ & & $2(10)$ & & $9(15)$ \\
\hline Psychosocial functioning (PSP) & $72(10.1 ; 48-90)$ & & $73(8.1 ; 58-87)$ & & $72.3(9.4 ; 48-90)$ & \\
\hline Functional impairment, yes ${ }^{\mathrm{a}}$ & & $18(45)$ & & $11(55)$ & & $29(48.3)$ \\
\hline Any axis I diagnosis (SCID-I) & & $14(35)$ & & $7(35)$ & & $21(35)$ \\
\hline Mood disorder & & $2(5)$ & & $5(25)$ & & $7(11.7)$ \\
\hline Anxiety disorder & & $6(15)$ & & $3(15)$ & & $9(15)$ \\
\hline Substance use disorder & & $7(17.5)$ & & $0(0)$ & & $7(11.7)$ \\
\hline Full clinical and functional recovery ${ }^{\mathrm{b}}$ & & $11(27.5)$ & & $6(30)$ & & $17(28.3)$ \\
\hline Time to remission from CHR [years] & $1.6(2.1 ; 0-10)$ & & $3.9(4 ; 0-9.7)$ & & $2.4(3.1 ; 0-10)$ & \\
\hline
\end{tabular}

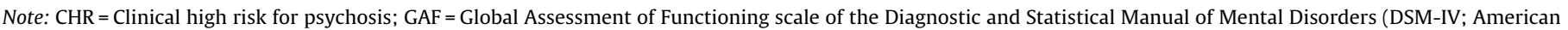

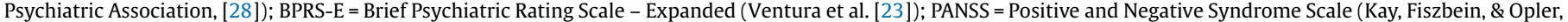

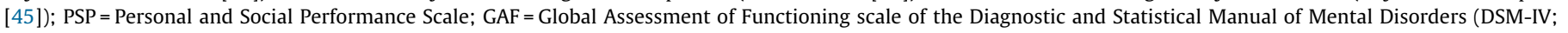

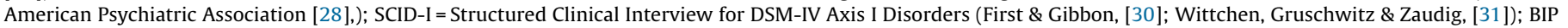
(Riecher-Rössler et al [46]).

a Personal and Social Performance Scale (PSP) total score $\leq 70$.

b Remission from CHR and absence of functional impairment and no axis I disorder.

\subsubsection{Rates of remission from $\mathrm{CHR}$}

The proportion of patients with a remission from $\mathrm{CHR}$ within the first 2, 3, 4, and 5 years of follow-up was estimated with the cumulative incidence curve as $23.7 \%, 32.8 \%, 36.4 \%$, and $37.4 \%$, respectively. Ten years after initial baseline an estimated

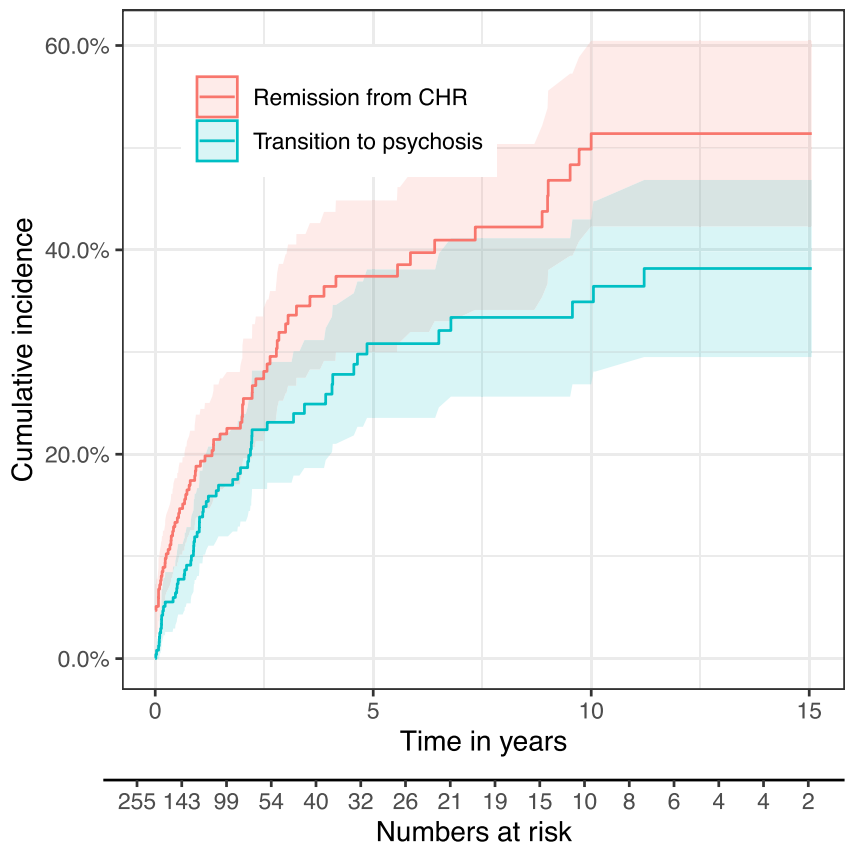

Fig. 2. Cumulative incidence curves.

Note: Estimated risks of remission from CHR and transition to frank psychosis over the whole follow-up period. Numbers at risk indicate CHR patients who are still in follow-up at this time point and neither remitted from their CHR nor transitioned. proportion of $51.4 \%$ had remitted, with no further remissions after that time point (for the rates of remissions at each year after initial baseline, see Fig. 2 and Table S2).

\subsubsection{Baseline predictors of remission from $\mathrm{CHR}$}

In the overall CHR sample, better psychosocial functioning at baseline was associated with a higher likelihood of remission from CHR during follow-up $(\mathrm{p}=0.003)$. Age, sex, positive and negative symptoms as well as cannabis use were not significantly associated with remission (see Table 3 ).

3.4. Clinical and functional outcome of the CHR-NT long-term followup sample $(\mathrm{n}=60)$

The mean follow-up duration of the CHR-NT long-term followup sample was $8.2 \pm 4.4$ (range: $0.1-16.6$ ) years. The average follow-up duration was $7.1 \pm 4.3(1.2-16.6)$ years of those with later remission from the CHR state and $2.5 \pm 3.2(0-15.1)$ years of those who neither remitted nor transitioned, respectively.

Of the $60 \mathrm{CHR}$-NT patients of the long-term follow-up sample, 51 (85\%) had remitted from their high risk status (CHR), 39 (65\%) had not any axis I diagnosis, 31 (51.7\%) showed good psychosocial functioning. All in all, only 17 (28.3\%) had fully recovered clinically and functionally. For further characteristics of the long-term follow-up sample see Table 2 and Fig. 3.

\subsubsection{Baseline predictors of remission from $\mathrm{CHR}$ and psychosocial functioning at long-term follow-up $(n=60)$}

There were no significant associations between any of the baseline variables and remission from CHR at long-term follow-up (all p-values > 0.05; see Table S3). However, higher age $(p=0.06)$ and less negative symptoms $(\mathrm{p}=0.09)$ at baseline were associated with better psychosocial functioning at long-term follow-up at a trend level (see Table S4). 
Table 3

Baseline predictors of remission from CHR in the whole sample $(n=255)$.

\begin{tabular}{|c|c|c|c|c|}
\hline $\begin{array}{l}\text { Outcome } \\
\text { (Competing Event) }\end{array}$ & Variable & Hazard Ratio & Confidence Interval & p-value \\
\hline \multirow{6}{*}{$\begin{array}{l}\text { Remission } \\
\quad \text { (Transition) }\end{array}$} & Age & 1 & $0.97-1.03$ & .83 \\
\hline & Sex & 0.99 & $0.62-1.56$ & .95 \\
\hline & Positive symptoms & 1.04 & $0.93-1.16$ & .49 \\
\hline & Negative symptoms & 0.96 & $0.88-1.05$ & .37 \\
\hline & Psychosocial & 1.04 & $1.01-1.06$ & $.003^{* * *}$ \\
\hline & Cannabis use & 0.76 & $0.4-1.4$ & .39 \\
\hline
\end{tabular}

${ }^{*} \mathrm{p} \leq .05$

$\mathrm{p} \leq .01$

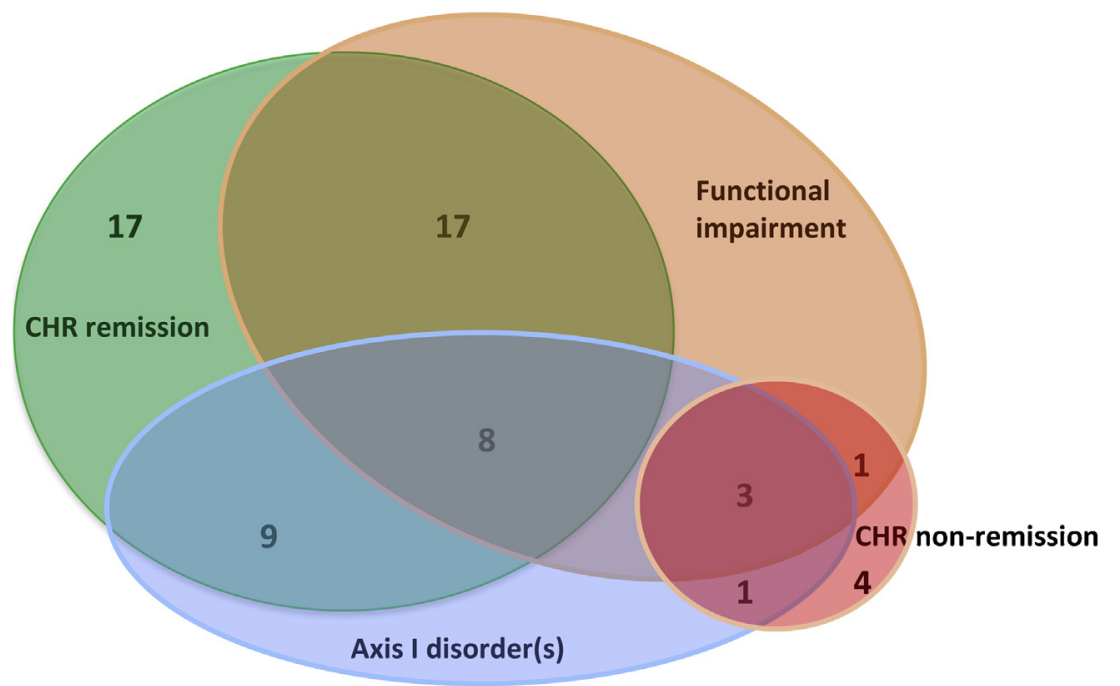

Fig. 3. Clinical and functional outcome of $\mathrm{CHR}$ patients without transition to frank psychosis at ultra-long-term follow-up ( $\mathrm{n}=60)$.

\section{Discussion}

We evaluated rates of transition and remission from the clinical high risk state and their predictors in a large sample of CHR patients over a follow-up period of up to 16 years. At the latest follow-up time, an estimated 38\% of the overall sample of 255 patients had transitioned to frank psychosis, $51 \%$ had remitted from their CHR state, and $11 \%$ continued to experience subclinical psychotic symptoms. A higher level of psychosocial functioning at baseline was associated with a higher likelihood of remission from the CHR state during the follow-up.

Of the 60 CHR patients who participated in our direct, personal long-term follow-up assessments (i.e., at an average of 8 years after baseline) and had not transitioned to psychosis, $85 \%$ had remitted from their CHR state, 35\% presented with at least one axis I diagnosis (apart from the CHR state), $48 \%$ showed poor functional outcome, and overall, only $28 \%$ had fully recovered clinically and functionally. This suggests that the majority of CHR-NT patients continue to experience clinical symptoms or functional impairments, even many years after initial identification. In this sample of CHR-NT patients, higher age and less negative symptoms at baseline were associated, at a trend level of significance, with better functional outcome at long-term follow-up.

\subsection{Transition to psychosis}

The present study estimated rates of transition for up to 16 years after initial referral, which - to our knowledge - is the longest time period that has ever been reported. Overall, we estimated that $26 \%$ of CHR patients had developed frank psychosis after 3 years,
$31 \%$ after 5 years, 35\% after 10 years, and 38\% after 16 years. Our estimated transition rates in the first 4 years of the follow-up are very similar to those reported in the most recent meta-analyses $[4,9]$. As expected [4], most transitions occurred during the first 2-3 years of follow-up. However, several of our CHR patients had experienced a "late transition" 4 or more years after initial identification.

So far, only very few studies have estimated cumulative transitions rates for periods longer than 4 years [35,36]. In line with our results, the study by Nelson et al [35] on 416 CHR patients revealed cumulative transition rates of $28 \%$ and $35 \%$ after 4 and 10 years, respectively. In contrast, the study by Fusar-Poli et al [36] on 509 CHR patients detected only few transitions after more than 4 years. However, they might have missed some late transitions as their follow-up was limited to 10 years and they had a relatively high rate of drop-outs.

The multiple late transitions revealed in our study and that of Nelson et al [35] support the importance of follow-up durations longer than three years. This is not only important to estimate the true rates of transitions but also to evaluate the outcome of CHR patients without transition to psychosis. The fact that there is quite a number of late transitions also challenges many studies on risk prediction, as most prediction models were developed based on samples with short follow-up durations and can therefore only make accurate predictions regarding the short term.

\subsection{Remission from $\mathrm{CHR}$}

In the whole sample of CHR patients, including those who transitioned, we estimated that $24 \%$ of $C H R$ patients had remitted 
from their CHR state after 2 years, 32\% after 3 years, 36\% after 5 years, and $50 \%$ after 10 and 16 years, indicating that a considerable number of CHR patients experience subclinical psychotic symptoms even many years after initial identification. The only other study that has estimated cumulative remission rates using competing risk survival analysis estimated $36 \%$ remissions after two years [26]. Our results are also similar to those of the meta-analysis of Simon et al. [5], which found a remission rate of $35 \%$ after two years.

Of the CHR patients without transition that participated in our direct long-term follow-up assessments $85 \%$ had remitted from their CHR state. This is about $10 \%$ higher than in other studies $[5,10,11,37]$ which might be explained by the shorter average follow-up durations of most of these studies compared to the on average 8 years of follow-up in our sample.

Persistence of attenuated psychotic symptoms might indicate an ongoing risk of transition to psychosis [38]. Recurrent symptoms might also point towards a moderate disposition to react to stress with subclinical psychotic symptomatology, but not full psychosis due to, e.g., comparably low vulnerability and/or good protective factors. Subclinical psychotic symptoms might also indicate other diagnoses such as affective disorder, posttraumatic stress disorder and borderline personality disorder.

\subsection{Baseline predictors for remission from $C H R$}

In the whole sample of CHR patients we found better psychosocial functioning at baseline to be associated with a higher remission rate. Not predictive were age, sex, positive symptoms, negative symptoms, or cannabis use. A similar study of Schlosser et al [26] found not only baseline psychosocial functioning but also lower levels of negative symptoms to increase the likelihood of remission. This discrepancy might be due to the large difference in the follow-duration (up to 2 vs. 16 years) and different measures of negative symptoms (i.e., SOPS vs. BPRS/ PANSS).

Poor psychosocial functioning is closely associated with (emerging) psychosis and might be a more stable marker for vulnerability to psychosis, i.e., non-remission from $\mathrm{CHR}$, than positive symptoms at baseline [39]. A subgroup of CHR patients might not be predisposed to psychosis but might suffer from nonpsychotic disorders associated with decreased psychosocial functioning and subclinical psychotic symptoms. CHR patients with better psychosocial functioning at baseline might have a higher resilience, including more internal and external resources such as a good social network and support, and a stable school or work environment. Those protective factors might contribute to their remission from CHR.

If only the CHR-NT patients that participated in our direct longterm follow-up assessments were considered, no significant associations between baseline predictors and remission from CHR were found. This is in line with a study of Ziermans et al [40]. However thismight also be due to a lack of statistical power as only few patients had not remitted from their CHR state $(n=9)$.

\subsection{Clinical and functional ultra-long-term outcome of CHR-NT patients}

The relatively high proportion of $\mathrm{CHR}$ patients without transition to psychosis diagnosed with clinical axis I diagnoses and/or showing poor psychosocial functioning at long-term follow-up is consistent with our recent review [15]. It suggests that most patients still require clinical attention and should be further examined. Despite the relatively large proportions of CHRNT patients presenting with non-psychotic disorders at long-term follow-up, recent studies have shown that the clinical high risk state for psychosis is not predictive for non-psychotic diagnoses $[17,41]$. The large number of comorbidities in CHR-P patients could at least partially be due to clinicians using other diagnosis as a substitute for a CHR diagnosis as the latter is not yet included in the DSM or ICD.

\subsection{Limitations}

We included patients from two different studies with slightly different study designs. While the FePsy study evaluated CHR patients aged 18 years or older, the Bruderholz study also included adolescents who made up almost half of its sample. Furthermore, the FePsy study used the BSIP for assessing CHR criteria, whereas the Bruderholz study used the SIPS. In addition, the initial follow-up duration was longer in the FePsy study (5-7 years) than in the Bruderholz study (2 years). Moreover, positive and negative symptoms were assessed with the BPRS-E in the FePsy study and the PANSS in the Bruderholz study. The small number of non-remitted patients in the CHR-NT sample possibly limits the statistical power of the analyses of predictors of remission from CHR. Nevertheless, our study is one of the first to extensively evaluate outcome of CHR patients over such a long follow-up duration, using an advanced methodological approach to estimate remission and transition rates for a large sample.

\subsection{Conclusions}

By investigating a relatively large sample of CHR patients over a very long follow-up duration of up to 16 years, we could demonstrate that several patients still transition to psychosis after the usual time period assessed in most previous studies. We also found that only a minority of CHR-NT patients had fully functionally and clinically recovered at long-term follow-up. So far, we have obviously underestimated the rate of late transitions as well as the long-term prevalence of clinical symptoms and functional impairments in CHR patients without transition. One implication of our study is that existing prediction models, which are mostly based on samples with short follow-up duration, can predict transition to psychosis only at short-term. Our study reinforces the need for longer follow-ups of patients at clinical high risk for psychosis to provide adequate clinical care and inform future research.

\section{Funding}

This work was supported by the Swiss National Science Foundation [grant number 32003B_159554].

\section{Declaration of Competing Interest}

None.

\section{Acknowledgements}

We thank all patients who participated in the study and shared their experience with us. Without them this research project would not have been possible. Furthermore, we thank the specialists who initially referred the patients.

\section{Appendix A. Supplementary data}

Supplementary data associated with this article can be found, in the online version, at https://doi.org/10.1016/j.eurpsy.2019.08.005. 


\section{References}

[1] Riecher-Rössler A, Gschwandtner U, Borgwardt S, Aston J, Pflüger M, Rössler W Early detection and treatment of schizophrenia: how early? Acta Psychiatr Scand Suppl 2006;(429):73-80.

[2] Häfner H, Riecher-Rössler A, Maurer K, Fätkenheuer B, Löffler W. First onset and early symptomatology of schizophrenia. Eur Arch Psychiatry Clin Neurosc 1992;242(2-3):109-18.

[3] Yung AR, Phillips LJ, McGorry PD, McFarlane CA, Francey S, Harrigan S, et al. Prediction of psychosis - A step towards indicated prevention of schizophrenia. Brit J Psychiat. 1998;172:14-20.

[4] Fusar-Poli P, Cappucciati M, Borgwardt S, Woods SW, Addington J, Nelson B, et al. Heterogeneity of psychosis risk within individuals at clinical high risk: a meta-analytical stratification. JAMA Psychiatry 2016;73(2):113-20.

[5] Simon AE, Borgwardt S, Riecher-Rössler A, Velthorst E, de Haan L, Fusar-Poli P. Moving beyond transition outcomes: meta-analysis of remission rates in individuals at high clinical risk for psychosis. Psychiatry Res 2013.

[6] Kempton MJ, Bonoldi I, Valmaggia L, McGuire P, Fusar-Poli P. Speed of psychosis progression in people at ultra-high clinical risk: a complementary meta-analysis. JAMA Psychiatry 2015;72(6):622-3.

[7] Riecher-Rössler A, McGorry PD. Early Detection and Intervention in Psychosis. 2016;181:179-89.

[8] Fusar-Poli P. The Clinical High-Risk State for Psychosis (CHR-P), Version II. Schizophr Bull 2017;43(1):44-7.

[9] Schultze-Lutter F, Michel C, Schmidt SJ, Schimmelmann BG, Maric NP, Salokangas RK, et al. EPA guidance on the early detection of clinical high risk states of psychoses. Eur Psychiatry 2015;30(3):405-16.

[10] Michel C, Ruhrmann S, Schimmelmann BG, Klosterkötter J, Schultze-Lutter F. Course of clinical high-risk states for psychosis beyond conversion. Eur Arch Psychiatry Clin Neurosci 2018;268(1):39-48.

[11] Lin A, Wood SJ, Nelson B, Beavan A, McGorry P, Yung AR. Outcomes of nontransitioned cases in a sample at ultra-high risk for psychosis. Am J Psychiatry 2015;172(3):249-58.

[12] Amminger GP, Schäfer MR, Schlögelhofer M, Klier CM, McGorry PD. Longerterm outcome in the prevention of psychotic disorders by the Vienna omega-3 study. Nat Commun 2015;6:7934

[13] Ising HK, Kraan TC, Rietdijk J, Dragt S, Klaassen RM, Boonstra N, et al. Four-year follow-up of cognitive behavioral therapy in persons at ultra-high risk for developing psychosis: the dutch Early Detection Intervention Evaluation (EDIE-NL) trial. Schizophr Bull 2016;42(5):1243-52.

[14] Cornblatt BA, Carrion RE, Auther A, McLaughlin D, Olsen RH, John M, et al. Psychosis prevention: a modified clinical high risk perspective from the Recognition and Prevention (RAP) program. Am J Psychiatry 2015;172 (10):986-94.

[15] Beck K, Andreou C, Studerus E, Heitz U, Ittig S, Leanza L, et al. Clinical and functional long-term outcome of patients at clinical high risk(CHR) for psychosis without transition to psychosis: a systematic review. Schizophr Res 2019.

[16] Fusar-Poli P, Rutigliano G, Stahl D, Davies C, De Micheli A, Ramella-Cravaro V, et al. Long-term validity of the At Risk Mental State (ARMS) for predicting psychotic and non-psychotic mental disorders. Eur Psychiatry 2017;42: 49-54.

[17] Webb JR, Addington J, Perkins DO, Bearden CE, Cadenhead KS, Cannon TD, et al. Specificity of incident diagnostic outcomes in patients at clinical high risk for psychosis. Schizophr Bull 2015;41(5):1066-75.

[18] Riecher-Rössler A, Pflueger MO, Aston J, Borgwardt SJ, Brewer WJ, Gschwandtner U, et al. Efficacy of using cognitive status in predicting psychosis: a 7-Year follow-up. Biol Psychiatry 2009;66(11):1023-30.

[19] Riecher-Rössler A, Gschwandtner U, Aston J, Borgwardt S, Drewe M, Fuhr P, et al. The Basel early-detection-of-psychosis (FePsy)-study - design and preliminary results. Acta Psychiatr Scand 2007;115(2):114-25.

[20] Simon AE, Gradel M, Cattapan-Ludewig K, Gruber K, Ballinari P, Roth B, et al. Cognitive functioning in at-risk mental states for psychosis and 2-year clinical outcome. Schizophr Res 2012;142(1-3):108-15.

[21] Shafer A, Dazzi F, Ventura J. Factor structure of the Brief Psychiatric Rating Scale - expanded (BPRS-E) in a large hospitalized sample. J Psychiatr Res 2017:93:79-86.

[22] Lukoff D, Nuechterlein KH, Ventura J. Manual for the expanded brief psychiatric rating scale. Schizophr Bull 1986;12:594-602.

[23] Ventura J, Lukoff D, Nuechterlein K, Liberman R, Green M, Shaner A. Manual of the expanded brief psychiatric rating scale. Int J Methods Psychiatr Res 1993; (3):227-43

[24] McGlashan T, Miller T, Woods S, Hoffman R, Davidson L. Instrument for the assessment of prodromal symptoms and States. In: Miller T, Mednick S,
McGlashan T, Libiger J, Johannessen J, editors. Early intervention in psychotic disorders. NATO science series D: (closed). 91. Netherlands: Springer; 2001. p. 135-49.

[25] Miller TJ, McGlashan TH, Woods SW, Stein K, Driesen N, Corcoran CM, et al. Symptom assessment in schizophrenic prodromal states. Psychiatr Q 1999;70 (4):273-87.

[26] Schlosser DA, Jacobson S, Chen Q, Sugar CA, Niendam TA, Li G, et al. Recovery from an at-risk state: clinical and functional outcomes of putatively prodromal youth who do not develop psychosis. Schizophr Bull 2012;38(6):1225-33.

[27] Morosini PL, Magliano L, Brambilla L, Ugolini S, Pioli R. Development, reliability and acceptability of a new version of the DSM-IV Social and Occupational Functioning Assessment Scale (SOFAS) to assess routine social functioning. Acta Psychiatr Scand 2000;101(4):323-9.

[28] American Psychiatric Association. Diagnostic and statistical manual of mental disorders: DSM-IV-TR. American Psychiatric Publishing, Inc; 2000.

[29] Juckel G, Schaub D, Fuchs N, Naumann U, Uhl I, Witthaus H, et al. Validation of the Personal and Social Performance (PSP) Scale in a German sample of acutely ill patients with schizophrenia. Schizophr Res 2008;104(1-3):287-93.

[30] First MB, Gibbon M. User's guide for the Structured clinical interview for DSMIV axis I disorders SCID-I: clinician version. Amer Psychiatric Pub Incorporated; 1997.

[31] Wittchen HU, Wunderlich U, Gruschwitz S, SKID Zaudig M, Strukturiertes Klinisches I. Interview für DSM-IV. Achse I: psychische Störungen. Interviewheft und Beurteilungsheft. Eine deutschsprachige, erweiterte Bearb. d. amerikanischen Originalversion des SKID I.. 1997.

[32] Rutigliano G, Valmaggia L, Landi P, Frascarelli M, Cappucciati M, Sear V, et al. Persistence or recurrence of non-psychotic comorbid mental disorders associated with 6-year poor functional outcomes in patients at ultra high risk for psychosis. J Affect Disord 2016;203:101-10.

[33] R Core Team. In: Computing RFfS, editor. R: a language and environment for statistical computing.. Vienna, Austria.

[34] Kleinbaum DG, Klein M. Survival analysis : a self-learning text. 3rd ed. New York: Springer; 2012 xv, 700 p. p..

[35] Nelson B, Yuen HP, Wood SJ, Lin A, Spiliotacopoulos D, Bruxner A, et al. Longterm follow-up of a group at ultra high risk ("Prodromal") for psychosis: the PACE 400 study. JAMA Psychiatry 2013;1-10.

[36] Fusar-Poli P, Nelson B, Valmaggia L, Yung AR, McGuire PK. Comorbid depressive and anxiety disorders in 509 individuals with an at-risk mental state: impact on psychopathology and transition to psychosis. Schizophr Bull 2014;40(1):120-31.

[37] Beck K, Andreou C, Studerus E, Heitz U, Ittig S, Leanza L, et al. Clinical and functional long-term outcome of patients at clinical high risk(CHR) for psychosis without transition to psychosis: a systematic review. Schizophr Res 2019.

[38] Nelson B, Amminger GP, McGorry PD. Recent meta-analyses in the clinical high risk for psychosis population: clinical interpretation of findings and suggestions for future research. Front Psychiatry 2018:9:502.

[39] Early detection and intervention in psychosis. In: Riecher-Rössler A, McGorry P, editors. State of the art and future perspectives.. Basel: Karger; 2016.

[40] Ziermans TB, Schothorst PF, Sprong M, van Engeland H. Transition and remission in adolescents at ultra-high risk for psychosis. Schizophr Res 2011;126(1-3):58-64.

[41] Woods SW, Powers [211_TD\$DIFF][181_TD\$DIFF]3rd AR, Taylor JH, Davidson CA, Johannesen JK, Addington J, et al. Lack of Diagnostic Pluripotentiality in Patients at Clinical High Risk for Psychosis: Specificity of Comorbidity Persistence and Search for Pluripotential Subgroups. Schizophr Bull 2018;44 (2):254-63.

[42] Riecher-Rössler A, Aston J, Ventura J, Merlo M, Borgwardt S, Gschwandtner U, et al. [The Basel Screening Instrument for Psychosis (BSIP): development, structure, reliability and validity]. Fortschr Neurol Psychiatr 2008;76(4):207-16.

[43] Peralta D, Studerus E, Andreou C, Beck K, Ittig S, Leanza L, et al. Exploring the predictive power of the unspecific risk category of the Basel Screening Instrument for Psychosis. Early intervention in psychiatry. 2018.

[44] Schultze-Lutter F, Ruhrmann S, Picker H, von Reventlow HG, BrockhausDumke A, Klosterkotter J. Basic symptoms in early psychotic and depressive disorders. Brit J Psychiat. 2007;191:S31-7.

[45] Kay SR, Fiszbein A, Opler LA. The positive and negative syndrome scale (PANSS) for schizophrenia. Schizophr Bull 1987:13(2):261-76.

[46] Riecher-Rössler A, Ackermann T, Uttinger M, Ittig S, Koranyi S, Rapp C, et al. [The Basel Interview for Psychosis (BIP): structure, reliability and validity]. Fortschr Neurol Psychiatr 2015;83(2):99-108.

[47] Klosterkötter J, Hellmich M, Steinmeyer EM, Schultze-Lutter F. Diagnosing schizophrenia in the initial prodromal phase. Arch Gen Psychiatry 2001;58 (2):158-64. 